\title{
Study on the Jingyou Mechanism of Corporate Strategic Behavior
}

\author{
Jongho Kim ${ }^{1, a}$, and Xinan Zhao ${ }^{2, b,{ }^{*}}$ \\ ${ }^{1}$ School of business administration, Northeastern University, Shenyang 110169, China \\ Institute of development strategy of S\&T, State academy of sciences, Pyongyang, DPRK \\ ${ }^{2}$ School of business administration, Northeastern University, Shenyang 110169, China \\ akimjongho@163.com, bxnzhao@mail.neu.edu.cn \\ *Xinan Zhao
}

Keywords: corporate strategic behavior, Jingyou, consciousness, organizational values.

\begin{abstract}
Today, the change of industrial environment affects all aspects of enterprise's development Relying on only traditional strategic behavior theories, it is difficult to solve the problems in the modern strategic management practice. Jingyou idea is based on the objective law of development of things, by which the enterprises can explore their strategic behaviors for a sustainable growth in new industrial environment. In this paper, it was carried out to study a mechanism of corporate strategic behavior based on Jingyou idea. The theoretical analysis was illustrated in terms of the consciousness and the formation of Jingyou consciousness through its evolution, the occurrence and development mechanism of corporate strategic behavior under the Jingyou environment, which can be helpful to realize the strategic management in line with sustainable development era.
\end{abstract}

\section{Introduction}

At present, there has been a great change in the global industrial environment. The symbiosis, relevance and interactivity between enterprises in an industry as well as the mutual penetration and interaction between different industries have gradually formed a new dynamic developing system, while the establishment of industrial ecosystem has been regarded as to an important way for sustainable development. The competition between enterprises has been likely to lose its universal significance. Instead, the coexistence, innovation and cooperation have become a new mechanism for value creation and growth. The enterprise's growth and the industry's development will be inseparable each other, i.e., former is a driving force of latter, while latter is a basis of former.

In this environmental change, all enterprises will face such strategic problems as the reformation of organizational values and value creation mode, the reorganization of relationship between other enterprises, which are very relevant to their survival and future development. The enterprises should execute the most reasonable strategic management to create their new growth points for sustainable development. The corporate strategic behavior is an important component of strategic management, the results of which directly affect the success or the failure of strategic management.

\section{Theoretical analysis}

\subsection{Literature review}

Gavetti et al. argued that corporate strategic behavior was a response of enterprise to environment and a resulting change in organizational structure [1]. Min explained that it was an action taken to acquire, maintain and develop the competitive advantage and profit by the choice of different strategies [2]. Anmin pointed out that it was an organizational behavior related to strategic management, including decision-making and executive behaviors [3]. Song argued that it was a strategic analysis and choice behavior based on the impact of various environmental factors and the cognition of decision-makers about it [4]. Grundy described that the interaction between cognition, emotion and individual could determine a mutual drive of organizational structure and strategic behavior [5]. Gavetti, Eggers et al. argued that the decision maker's cognition had a significant impact on the strategic behavior [6,7]. 
Hailin explained that the corporate strategic behavior included the pre-planned and reactive behaviors, while would depend upon rational factors as well as non-rational factors [8].

Above researches provided the useful technical support for explaining the causes and motivations, the components and effects of corporate strategic behavior. However, most of them emphasized to achieve the goal of strategic management by the competition between enterprises in industry based on a self-centered values. In addition, there was a lack of analysis on the occurrence and development of strategic behavior from the standpoint of objective law of development of things.

\subsection{Jingyou idea and purpose of study}

In 2006, Xinan et al. put forward the Jingyou idea. They argued that people should strive to explore and use natural laws to exhibit their own excellence in the change of environment and the creation of benefits for mankind rather than narrow competition, which was named "Jingyou". They explained that the master of behavior was an objective being with social attribute existed in organizational environment, the values and behavior of which directly affect not only its growth but the development of its organization. Therefore, it should pursue the common development of organization, and realize its own values through the contribution to organization [9]. Jingyou idea, which implied the strategic idea of sustainable development era, has contributed to develop the organizational behavior and management theories because it was scientific, objective and easy to accept.

The purpose of study in this paper is to reinterpret the relationship of behavioral elements and then suggest a new mechanism of corporate strategic behavior under the guidance of Jingyou idea.

\subsection{Consciousness and its evolution, formation of Jingyou consciousness}

Kurt pointed out that the individual behavior was an interaction between its internal factors and environment, which was expressed as follow: $B=f(P, E)$, where $B$ was the direction and intensity of behavior, $P$ was the internal factors (consciousness and ability), and $E$ was the environment [10]. But from the standpoint of master of behavior, it is the reaction of internal factors to environment, so its master is just individual. The environment is nothing but its object which indirectly affects ability through consciousness. The consciousness determines its direction, while the ability affects its intensity. From the relationship between behavioral elements, the above function can be rewritten as follows: $B=f(C, A)$, where $C$ is an individual consciousness of ability and environment, which may be expressed as $C=f_{1}(A, E)$, that is, the behavior is an interaction between consciousness and ability. The consciousness is the most crucial among them, i.e., the behavior is its embodiment.

From the biological viewpoint, the consciousness generally experiences four stages of evolution: 1) the germination: the discovery of things by feeling, vision and hearing; 2) the formation: the understanding of its essence and law; 3) the refinement: the judgment as to whether or not its use is favorable by using the accumulated knowledge; 4) the maturity: the determination of goal and way of behavior according to the results of cognition and judgment (see Fig. 1). Fig. 1 also shows the impact of values on the evolution of consciousness. Different values produce different evolutionary results. If the values are self-centered, the results may be given as personal goal, competition and monopoly. If the values pursue the co-development of individual and its group, they will include group goal, cooperation and coexistence. If the values reflect the new ideas of natural or social development, they may be challenge and innovation, otherwise, they are represented as avoidance and imitation.

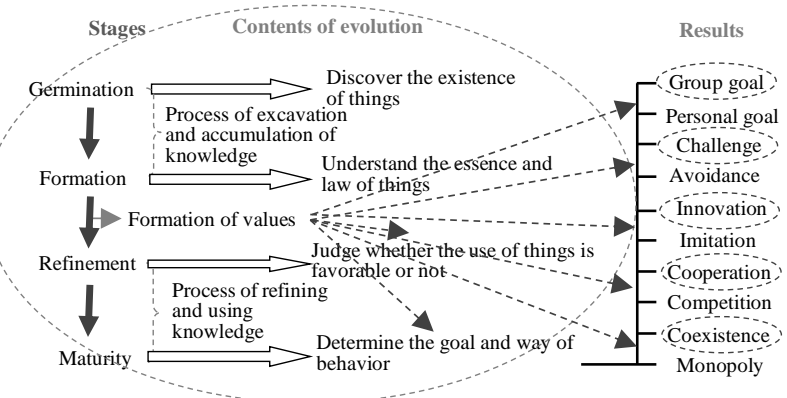

Fig. 1. The evolutionary process of consciousness 
From the perspective of Jingyou, the evolution of consciousness implies the meaning of Jingyou. Jingyou is an individual behavior to explore and use natural laws to exhibit its excellence, the values of which are harmony, innovation and co-development. In Fig. 1, the discovery, understanding and judgment are the preconditions of Jingyou behavior, while such results as group goal, innovation, cooperation and coexistence reflect its values, which shows that the evolution of consciousness can generate Jingyou consciousness. The "Jingyou consciousness" refers to the subjective reflection of individual on the objective things under the values of Jingyou, which is based the objective laws of nature and society. If the values are self-centered, the evolution leads to a competitive consciousness.

\subsection{Jingyou mechanism of corporate strategic behavior}

The corporate strategic behavior is the organizational behavior of strategic decision-makers, which includes the two concepts of organizational behavior and strategy. The organizational behavior is the response of an organization to its environment caused by endogenous or exogenous stimulus. The strategy reveals the goal and direction of behavior, but it may be changed according to the strategic consciousness of decision-makers, which may be divided into internal and external ones. Former refers to the cognition and practical will to rational or non-rational factors including strategic goal, ability, organizational structure, etc., which can protect enterprises against losing their way or out of control in the choice of major strategies. Latter is the dynamic cognition and adaptive will to the external environment such as politics, economy, culture, technology and their future changes, which allows enterprises to make the dynamic adjustment and transformation of their strategies with the change of external environment. According to the above relationship between behavioral elements, the corporate strategic behavior can be redefined as follows: the corporate strategic behavior is an interaction between strategic consciousness and ability of enterprise during strategic period. In a dynamic environment, it and its elements may be expressed as follows:

$$
\begin{aligned}
& B_{t}=f\left(C_{t}, A_{t}\right), \\
& C_{t}=f_{1}\left(A_{t}, E_{t}\right), \\
& A_{t}=f_{2}\left(B_{t}\right), \\
& E_{t}=f_{3}\left(B_{t}\right),
\end{aligned}
$$

As seen from the equations, the strategic behavior and its elements all have dynamic features. As the strategic behavior changes, the ability and environment change, and further will lead to the change of strategic consciousness, which will form another strategic behavior. These processes are repeated at every stage of strategic management including the strategic analysis, selection and execution.

The strategic consciousness also experiences the evolutionary process, where the organizational values play the most important role. It determines the characteristics of strategic consciousness, and affects the strategic behaviors at each stage of strategic management. If it needs a co-development of enterprise and industry, the strategic consciousness has Jingyou characteristic, and its evolutionary results are as follows: 1) the common goal of enterprises in industry; 2) the exploration of enterprise's growth way based on the objective law of things; 3 ) the cooperation between other enterprises. If it pursues a self-centered growth, the strategic consciousness possesses a competitive characteristic, while its evolutionary results will be expressed as the acquiring of absolute competitive advantage in industry, that is, the enterprise only seeks economic profit and market expansion, and believes that imitation is more important than innovation. Of course, with the change in the internal and external environment, the organizational values will also be changed. According to the evolutionary results, the strategic behavior will be represented as Jingyou strategic behavior or competitive strategic one.

In fact, the competitive strategic behavior has a positive effect on both enterprise and industry in the early stage of industry's development, and the performance of entire industry can produce the effect of " $1+1=2$ ". However, the capacity of market and resource in an industry is not unlimited, which leads to the excessive competition between enterprises to capture more markets and resources, and further may bring about the effect of " $1+1 \leq 2$ ". Jingyou strategic behavior requires that the individual advantage of enterprise must be maximized under the principle of combining the interests 
of both enterprise and industry, which promote the effective cooperation in the resource and ability between enterprises in industry, so that can get the effect of " $1+1 \geq 2$ ". Fig. 2 shows the occurrence and development mechanism of corporate strategic behavior in each stage of strategic management.

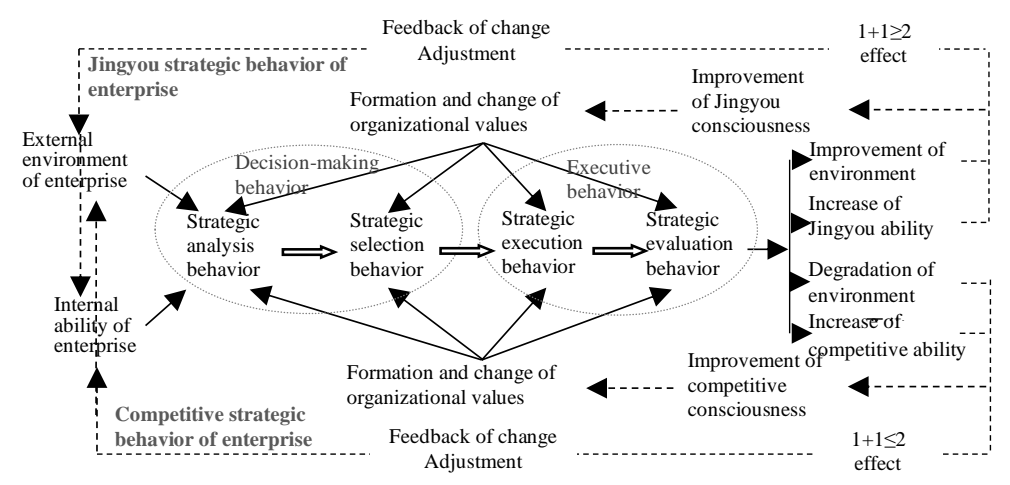

Fig. 2. The mechanism of occurrence and development of corporate strategic behavior

\section{Summary}

This paper proposed a new mechanism of corporate strategic behavior on the basis of Jingyou idea: 1) it was carried out to reinterpret the relationship between behavioral elements from the standpoint of master of behavior; 2) it was given to explain the evolution of consciousness and the formation of Jingyou consciousness; 3) the occurrence and development mechanism of strategic behavior was illustrated through the analysis of impact of organizational values and strategic consciousness on strategic behavior. The results of study will be of significance to develop the strategic behavior theory and to realize the most reasonable strategic management under the modern industrial environment.

But the Jingyou mechanism of corporate strategic behavior suggested in the paper is still limited to one industry. From the standpoint of national economy, it must be developed into an open mechanism to overcome the obstacles to the collaboration with the enterprises in different industries.

\section{Acknowledgment}

This research was financially supported by the National Natural Science Foundation of China (Grant NO. 71271048$)$.

\section{References}

[1] Gavetti G and Rivkin J W, How strategists really think: Tapping the power of analogy, Harvard Business Review, vol. 83, pp. 54-63, 2005.

[2] Min Luo, Review of corporate strategic behavior, Foreign Economics \& Management, vol. 34, pp. 35-44, 2012.

[3] Anmin Li, Optimization and Reconstruction to the Monitoring Index System of Regional \& Technology progress, Science of sciencs and S\&T Management, vol. 27, pp. 129-131, 2006.

[4] Song Wang, Research on the role of competitive intelligence in the strategic behavior of internet companies, Wuhan University, 2016.

[5] Grundy T, Harnessing strategic behavior: Why personality and politics drive company strategy, Financial Times, 1998.

[6] Gavetti G, The new psychology of strategic leadership, Harvard Business Review, vol. 89, pp. 118-125, 2011.

[7] Eggers J. P and Kaplan S, Cognition and Renewal; Comparing CEO and Organizational Effects on Incumbent Adaptation to Technical Chang, Organization Science, vol. 20, pp. 461-477, 2009. 
[8] Hailin Lan, Strategic Management: Corporate Strategic Behavior in the Chinese Situation, Beijing, Mechanical Industry Press, 2012.

[9] Xinan Zhao, Chunhong Zhu, and Yanmei Wang, Jingyou Evaluation Theory, Method and Application, Science Publishing House, 2012.

[10] Binsi Luo, Organizational Behavior, Beijing, China Renmin University Press, 2005. 